\section{AN ESSAY}

\author{
on
}

\section{CONTAGION: ITS NATURE AND MODE OF ACTION.*}

\section{BY JOHN SIMON, C.B., F.R.S.}

[THIs paper was written in April 1878, as an article for Dr. Quain's forthcoming Dictionary of Medicine, and, from the intention with which it was written, has the present date has been added.-November, 1879, J. S.]

IT is not yet possible to say, in any universal sense, with regard to the metabolic contagia, what is the essential constitution of "contagious matter", or what the intimate nature of the "transforming power" which the particle of such matter exercises on the particles which it infects. As regards the question of the Force, chemists, when they refer in general terms to the various acts which they designate acts of fermentation, allege that certain processes of change in certain sorts of organic matter induce characteristic changes in certain other sorts of organic matter, not by the common chemical way of double decomposition with reciprocally new combinations, but (so to speak) as a mere by-play or collateral vibration-effect of the chemical force which is in movement; and, though language can hardly be more vague than this for any scientific purpose, it expresses clearly enough the conviction of experts that a certain great force in nature lies beyond their power even of definite nomenclature, much more of exact identification and measurement. In that most interesting, but most difficult and hitherto almost uninvestigated, branch of chemical dynamics, we are supposed to have our nearest clue to the scientific problems of the present subject-matter. It may be conceded that the "contact-influences" which are dimly recognised as causing the fermentatory changes of dead organic matter have apparent analogues in many of the morbific influences of contagion: for the changes which chemists call "fermentatory" are all catalytic or disintegrative of the organic compounds which they affect ; and when living protoplasm is brought by contagion into processes of characteristic decay, the analogy seems sufficiently close to justify the word "zymotic" in the naming of the nature of the process. But it must not be forgotten that, among immediate effects of contagion in the living body, are cases wherein the process (so far as we can yet see) is primarily not catalytic or disintegrative, but, on the contrary, anaplastic or constructive. Thus, when tubercle gives rise to tubercle, whether by secondary and tertiary infection in a single diseased body, or by infection from the sick to the healthy, each new tubercle which the contagion brings into being is a growth-product of the texture which bears it. And, similarly, when the innumerable variet:es of cancerous tumour propagate themselves by contagion, each after its special type, in the bodies of the respective sufferers, it is growth, not disintegration, which we first see. It would seem that in those cases of anaplastic "contact-influence" something far beyond the analogy of chemical fermentations must be involved; and, in view of some of them, the physiologist has to bethink himself of the analogy of that "contact-influence" which becomes the mainspring of all normal growth and development when the ovum receives spermatic impregnation.- As regards the ultimate organic constitution of the several metabolic contagia (each of them of course abstracted from accidental admixtures, and seen or conceived in the smallest and simplest units of quantity and quality in which its specific force can be embodied) modern research seems more and more tending to show that the true unit of each metabolic contagium must either be, or must essentially include, a specific living organism, able to multiply its kind. For, with regard to those other contagia (as we may properly call them) which spread fermentatory processes in common external nature, and of which it is as clear as of the morbific contagia that they multiply themselves in proportion as they act, it seems to be established beyond reasonable doubt that the "self-multiplication" of each of them as it acts is the infinite multiplication of a specific microphyte ; and that this microphyte (acting apparently by means of a matter which it produces and from which it can be mechanically separated) is the essential originator of the fermentation. $\uparrow$ This being the case in regard to those

* Concluded from page 926 of last number.

$t$ The doctrine to which the words in parentheses refer (that the microphyte is not itself the ferment, but the producer and evolver of the ferment) tends to bring the case of these ferments into parallelism with that of the chylopoietic and other functional ferments which more highly organised creatures produce for the purposes of their own ferments which more highly organised creatures produce for the purposes of their own (say certain gastric cells) and their not-live product (say pepsin) is already familiar. fermentations, it seems probable that the same is in substance true of the specific morbid changes which extrinsic contagia produce in the materials of the living body; probable, namely, that low self-multiplying organic forms, specific in each case for the particular disease which is in question, are essential to each morbid poison; that the increase of each contagium as it acts is the characteristic self-multiplication of a living thing; and that this (however obscure may yet remain its mode of operation) is the essential originator of change in the affected materials of the diseased body. The fact that low organic forms of the sorts now spoken of have often, or generally, been seen in the morbid products and tissues of persons with zymotic disease, would not by itself be a proof, or nearly a proof, that the forms are causative of the morbid change : for obviously they might be mere attendants on the necrosis and decomposition of bodily material, availing themselves of the process (just as certain insects would) to feed and multiply : and in many of the cases in which micrococci have been seen in morbid material, no direct proof could be given that the meaning of their presence was more than that. There are, however, some cases in which this proof has been completely established; and, although such cases are at present but few, the significance of each of them in aid of the interpretation of other cases is of the highest importance. The researches of successive able observers in regard of the splenic fever of farm-stock, and those of Dr. Klein in regard of the "pneumo-enteritis" (as he names it) of swine, have shown that in each of these cases the microphyte which attends the disease is botanically specific; that it and its progeny can be conducted through a series of artificial cultivations apart from the animal body; and that germs thus remotely descended from a first contagium will, if living animals be inoculated with them, breed in these animals the specific disease. It is equally well known that the organism (spirilla) which is found multiplying in the blood during the accesses of relapsing fever is botanically specific; but, in regard to this disease (which is not known to affect any other animal than man), experimental proof is still wanting that the microphytc, after long artificial cultivation, will be able to infect with the disease. Studies as complete as those which have been made in splenic fever and pneumo-enteritis will no doubt sooner or later be made in regard to many other of the diseases, but their progress will necessarily be slow; partly because the objects which have to be scrutinised, and to which specific characters have to be assigned, are so extremely minute, and often so similar among themselves, that none but very skilled and very patient microscopical observers are competent to pronounce on them; and partly again because the conditions of the case are such as to limit very closely the field within which the essential experimental observations can be made. Meanwhile, however, the two diseases, regarding which the larger knowledge has been obtained, must be regarded as highly suggestive in regard of other diseases of the same pathological group, and particularly as giving importance to fragments of evidence (not by themselves conclusive) which have been gathered of late years in studies of some of these other diseases. Eminently this is true of the large family of the septic infections-including on the one hand erysipelas and pyæmia with its congeners, and having on the other hand tuberculosis intimately associated with it ; and almost equally it is true of enteric fever and cholera and diphtheria, and of the small-pox of man and beast. Thus, though it would be at least premature to say of these diseases that they certainly have as their contagia microphytes respectively specific to them, it seems at present not too much to say that probably such will be found the case; and, if as much may not yet be said of many other diseases which are due to metabolic contagia, it must be remembered that the right lines of study relating to contagia in this point of view have not till within very recent times been opened.

Of the natural history of the contagia, considered independently of the part which they play in the living body, there are hitherto only the beginnings of knowledge. The absolutely first origin of contagia may perhaps not be more within reach of scientific research than the absolutely first origin of dog or cat ; but their nearer antecedents-the states out of which they come when first about to act on the living body, and generally the variations which they and the common ferments exhibit under natural and artificial changes of circumstance, are within easy reach of investigation; and those humbler studies are likely to give very useful results. For some of our cases, we seem to have an instructive analogy in the facts which Professor Mosler has put together in explanation of the blue-milk contagium of dairies : facts showing that the omnipresent penicillium glaucum, if its spores happen to alight in particular (morbid) sorts of milk, will operate distinctively on their casein as an anilin-making ferment, rendering the milk blue and poisonous, and imparting to each drop of it the power to infect with a like zymosis any normal milk to which it may be added.* In our own more special field,

* Virch. Arch., vol. xliii. 
pathologists have already learnt that certain of the so-called "morbid poisons" - the contagia of erysipelas, pyæmia, and tuberculosis are intimately related to the common ferment or ferments of putrefaction ; and that the most vehement of these contagia can be developed by the artificial culture of successive transmissions in the living body from the comparatively mild contagium of any "common" inflammatory process."

Two other directions suggest themselves as likely to lead to fields of useful observation and experiment. On the one hand, in comparative pathology, and with the tracing of contagion from animal to animal, there is the possibility that at last some lower and relatively worthless order of animals may be found the starting-ground of fatal infections for higher orders ; and this, perhaps, by contagia which in their former relations are of mere inflammatory significance. On the other hand, in geographical pathology, and with the tracing of contagion from place to place, local centres of contagium-origination may possibly be found, in which the contagium, before it enters the animal body, will show itself an independent microphyte of the earth, first operating on the animal body as the essential force in a local malaria. Some of the worst pestilences known to the human race-yellow fever, cholera, perhaps plague, and also some of the diseases of cattle, have in their history facts which suggest that sort of interpretation : the supposition, namely, that certain microphytes are capable of thriving equally (though perhaps in different forms) either without or within the animal body; now fructifying in soil or water of appropriate quality, and now the self-multiplying contagium of a bodily disease. In regard to our own common ague-poison, there seems every reason to suspect that its relation to soil is that of a microphyte; and though we know ague only as practically a non-contagious disease, we do not know that any little transfusion of blood from sick to healthy would not show it to be (in that way) communicable from person to person. [See Postcript below.]

It needs hardly be said that exact scientific knowledge of the contagia, and of their respective modes of operation, is of supreme importance to the prevention of disease. With even such knowledge of them as already exists, diseases which have in past times been most murderous of mankind and the domestic animals can, if the knowledge be duly applied, be kept comparatively or absolutely in subjection; and the fact that at the present time fully a fifth part of the annual mortality of the population of England is due to epidemics of contagious disease is only because of the very imperfect application hitherto made of that knowledge. In the present article, it is not necessary to state in detail the practice which ought to be adopted in the various different cases of infectious disease ; but briefly it may be said that one principle is at the root of ail such practice, whatever the disease to which it relates. This principle, which of course becomes more and more important in proportion as the infection is dangerous, and as the persons whom it would endanger are many, is the principle of thoroughly effective separation between the sick and the healthy : a separation which, so far as the nature of the disease requires, must regard not only the personal presence of the sick, but equally all the various ways, direct and indirect, by which infective matters from that presence may pass into operation on others. Especially as regards the diseases which make serious epidemics, the principle of isolation is not carried into effect unless due care be taken to thoroughly disinfect in detail all infective discharges from the sick, and all clothing and bedding and towels and like things which such discharges may have imbued, and finally, as regards certain contagia, the rooms in which the cases have been treated; and in order to secure these objects, it is essential in all grave cases to make such nursing-arrangements and such arrangements of the sick-room (whether private or in hospital) that no retention or dissemination of infectious matters will escape notice. It is likewise essential that all who attend on the sick should be careful not to carry contagion to other persons, as they may but too easily do, particularly in scarlatina and in certain traumatic and puerperal infections, if they omit to take special precautions against the danger. See articles on Quarantine and Disinfection, and articles on the special diseases.

The social conditions through which, in our own country at the present time, the more fatal infectious diseases are enabled to acquire epidemic diffusion are chiefly such as the following :- that persons first sick in families and districts, instead of being isolated from the healthy and treated with special regard to their powers of spreading infection, are often left to take their chance in all such respects; so that, especially in poor neighbourhoods, where houses are often in several holdings,

* See particularly Professor Sanderson's papers in successive yearly volumes of $R e$ ports of the Medical Officer of the Privy Council from 1868 to 1877 . It concerns the second fact mentioned in the text to remember that apparently every" common inflammatory process" includes more or less of textural changes which are necrotic and of septic tendency. See Holmes's System of Surgery, first edition, article "Inflammation". and where always there is much intermingling of population, a first case if not at once removed to a special establishment, will almost of necessity give occasion to many other cases to follow ; - that persons with infectious disease, especially in cases of slight or incipient attack, and of incomplete recovery, mingle freely with others in workplaces and amusementplaces of common resort, and, if children, especially in day-schools, and that such persons travel freely with other persons from place to place in public conveyances; - that often, on occasions when boardingschools have infectious disease getting the ascendant in them, the schools are broken up for the time, and scholars, incubating or perhaps beginning to show infection, are sent away to their respective, perhaps distant, homes ; - that keepers of lodging-houses often receive lodgers into rooms and beds which have recently been occupied by persons with infectious disease and have not been disinfected;-that persons in various branches of business relating to dress (male and female) and to furniture, if they happen to have infectious disease, such as scarlatina or small-pox, on their premises, probably often spread infection to their customers by previous carelessness as to the articles which they send home to them, and that laundries further illustrate this sort of danger by carelessness in regard toinfected things which they receive to wash;-that purveyors of certain sorts of food, if they happen to have infectious disease on their premises, by carelessness spread infection to their customers; - that streams and wells with sewage and other filth escaping into them are most dangerous means of infection, especially as regards enteric fever and cholera, and that great purveyors of public water-supplies, so far as they use insufficient precautions to insure the freedom of their water from such risks of infectious pollution, represent in this respect an enormous public danger; - that ill-conditioned sewers and house-drains, and cesspools receiving infectious matters, greatly contribute to disseminate contagia, often into houses in the same system of drainage, and often by leakage into wells. Of the dangers here enumerated, there is perhaps none against which the law of England does not purport in some degree to provide. At present, however, they all are, to an immense extent, left in uncontrolled operation; partly because the law is inadequate, and partly because local administrators of the law often give little care to the matter ; but chiefly because that strong influence of national opinion which controls both law and administration cannot really be effective until the time when right knowledge of the subject shall be generally distributed among the people, and when the masses whom epidemics affect shall appreciate their own great interest in preventing them.

Whenever that time shall come, probably the public good will be seen to require, with regard to every serious infectious disease which is apt to become epidemic, that the principles which ought to be accepted in a really practical sense, and to be embodied in effective law, are somewhat as follows: (I) that each case of such disease is a public danger, against which the public, as represented by its local sanitary authorities, is entitled to be warned by proper information; (2) that every man who in his own person, or in that of anyone under his charge, is the subject of such disease, or is in control of circumstances relating to it, is, in common duty towards his neighbours, bound to take every care which he can against the spreading of the infection; that, so far as he would not of his own accord do this duty, his neighbours ought to have ample and ready means of compelling him ; and that he should be responsible for giving to the local sanitary authority proper notification of his case, in order that the authority may, as far as needful, satisfy itself as to the sufficiency of his precautions; (3) that so far as he may from ignorance not understand the scope of his precautionary duties, or may from poverty or other circumstances be unable to fulfil them, the common interest is to give him liberally out of the common stock such guidance and such effectual help as may be wanting ; (4) that so far as he is voluntarily in default of his duty, he should not only be punishable by penalty as for an act of nuisance, but should be liable to pay pecuniary damages for whatever harm he occasions to others ; (5) that the various commercial undertakings which in certain contingencies may be specially instrumental in the spreading of infection-water companies, dairies, laundries, boardingschools, lodging-houses, inns, etc., should respectively be subject to special rule and visitation in regard of the special dangers which they may occasion; and that the persons in authority in them should be held to strict account for whatever injury may be caused through neglect of rule ; (6) that every local sanitary authority should always have at command, for the use of its district, such hospital-accommodation for the sick, such means for their conveyance, such mortuary, such disinfection-establishment, and generally such planned arrangements and skilled service, as may, in case of need, suffice for all probable requirements of the district.

Persons who are imperfoctly acquainted with the scientific and social facts relating to the present subject matter, or who have never seriously considered them, may think it would be over-sanguine to expect any 
general recognition of principles so peremptory as the above may at first appear to them ; but, if so thinking, they would perhaps have underestimated the rapidity with which knowledge is now increasing as to the common interests and mutual duties of mankind in respect of dangerous infectious disease. Fourteen years ago, when the so-called cattleplague or steppe-murrain was imported afresh, as a long-forgotten disease, into this country, and was found to affect very large pecuniary interests, primarily of the chief landowners of the United Kingdom, but secondarily of other classes, an immensely valuable stimulus was given to the education of the country, and especially of its legislature, in regard to the preventability of the infectious diseases. And the remarkable zeal and ability which have been shown in providing adequate laws and admirable administrative arrangements against the diffusion of steppe-murrain and other infectious diseases of Farm-Stock are not likely to be found permanently absent in relation to the interests of Human Life when once the true bearings of the subject shall have got to be popularly understood.

[Since the writing of the above, a year and a half ago, there seems to have been made, in one of the directions referred to, an important and most interesting addition to positive knowledge. In two recent numbers (July and October 15 th) of the Archiv für experimentelle Pathologie, Professors Klebs and Tommasi-Crudeli report the particulars of a research recently conducted by them at Rome with regard to the essential cause of the ague which is endemic about that city; and, so far as can be judged from that account, the doctrine that aguepoison is a microphyte of malarious soil is no longer a mere matter of suspicion (as my text expresses it) but is a matter of experimental certainty. The investigators, namely, declare that they can isolate from malarious soils and their atmosphere definite microphytic forms capable of separate cultivation; and that, when successive generations of this "bacillus malariæ" (as they name it) have been cultivated in successive quantities of an indifferent fluid, subcutaneous inoculation of rabbits with any final fluid in which the bacillus is germinating will give ague to the subjects of the experiment. The argument of my text (in the section relating to the natural history of contagia) may suggest how extremely interesting it would be to ascertain whether, when animals are under influence of the bacillus malaria, the fever can be propagated from them to healthy animals by means of small transfusions of blood. -November 1879. J. S.]

Abergavenny.- The number of deaths registered in Abergavenny last year is the lowest on record. The death-rate is in the proportion of 17 per 1,000 of the estimated population, and its lowness is chiefly attributable to the almost entire immunity from zymotic diseases. Only eight deaths from this class occurred, and even among these there are two or three whose place in the class is questionable. Mr. Steel reports a still increasing improvement in the sanitary state of the town, especially in the habits of people dwelling in the closest and worst built courts. There still remains a good deal to do, and the questions of sewage disposal and trade nuisances seem to deserve the earnest attention of the local authority.

REIGATE (URBAN AND RURAL).- - The borough of Reigate, as has already been shown in Dr. Thorne Thorne's report on the recent epidemic of typhoid fever at Caterham, is usually remarkably healthy. The rate of mortality during the five years of Mr. Jacob's appointment has been lower in this district than in any other portion of the combination. Last year, it was 14.3 per 1,000 , or slightly $(.2)$ above the average of the last five years. The deaths (16) from zymotic diseases were very much fewer than in any of the four preceding years, and were at the low rate of 9 per I, 000 . Three cases of small-pox are recorded; four cases of scarlet fever in Reigate and a small outbreak at the Earlswood Asylum; attacks of diphtheria in two houses; two cases of enteric fever ; and a somewhat extended prevalence of whooping-cough. In all these cases, the proper remedial measures were taken. Some of the polluted wells that still remain in the district have been closed, and a supply taken from the water companies. Sewerage and house-drainage are also progressing satisfactorily. The rural district of Reigate is also a very healthy one, the death-rate being 15.3 per $\mathrm{I}, 000$ of the estimated population. The deaths from zymotic diseases were Io per cent. of the deaths from all causes, and at the rate of 1.6 per 1,000 . Small-pox, measles, and whooping-cough were not prevalent in any part of the district. Thirty-nine cases of scarlatina, 28 of diphtheria, and 10 of enteric fever were reported. As regards diphtheria, Mr. Jacob could, in many instances, find no connection between the cases, though one outbreak (at Horley) was clearly traceable to the school. Schemes for the sewage disposal of Merstham and Horley are now in a forward state, and a code of by-laws has probably by this time received the sanction of the Local Government Board.

\section{REMARKS}

ON

\section{A N I M A L V A C C I N A T I O N.}

\section{A Paper read at the Conference of the Parliamentary Bills Com- mittee of the British Medical Association, on Animal \\ Vaccination, December 4 th, 1879.*}

By E. W A R L O M N T, M.D.,

Member of the Royal Academy of Medicine of Belgium; Director of the State Vaccine Institute at Brussels, etc.

IT is not, however, sufficient that the lymph from the calf be harmless, it must be inoculable and preservative against small-pox. It must be inoculable. But how can it be otherwise? What was it, in fact, but animal lymph which caused Jenner to make his immortal discovery? When Jenner had the inspiration which has made his name revered, what had he before his eyes but a person who, having had the abraded epidermis brought into contact with an animal-vaccine pustule, had been inoculated with the matter of that pustule? This person had thus unwittingly practised upon himself animal vaccination. Animal vaccination is, then, the progenitor of all other vaccination, present, past, and future, and if it had not been efficacious, vaccination would have been unknown. Of what use is it to push demonstration further? Animal vaccination is-and we profit by this opportunity to define it-nothing else than the maintenance of original vaccinia (cowpox) upon its native soil, where it is cultivated by successive inoculations, without ever having recourse to other sources. It is not, as our opponents are pleased to say, thinking thus to overthrow our proceedings, lymph taken from children, and replanted on calves (a method known as "retrovaccination"), but lymph which has never received any other aliment than that of its native soil. How then could it lose its qualities, and what analogy could be pleaded for the belief that it was necessary that such virus, to live and prosper, should be cultivated upon strange soil?

Perhaps I shall be asked to adduce, in support of my statements, comparative statistics. I should regret that such a request were addressed to me, for I should feel bound to take no notice whatever of it. I would never consent to furnish as proof such an element of appreciation, because I should reject it as coming from my opponents. Comparative statistics are only valuable when all the conditions of a proper comparison can be brought together. It would be necessary, to arrive at any reliable result in this respect, to have identity of vaccinated subjects, identity of condition in the lymph employed (living or preserved, in the dry or liquid form), identity of the age of the lymph; identity, moreover, of the capacity and judgment of the experimenters. I shall wound no one, I think, by remarking how very important it would be, in such a question, for statisticians to put on one side their predilections, and also what difficulty there would be in getting identity of conditions, all of which are indispensable. Comparative statistics, even if they were made by Aristides, would only satisfy himself.

It would not be quite the same with statistics giving absolute results, since they cannot be left to the caprice of opinion. The subjoined appears to me to unite the good qualities of absolute exactitude and truth. In 1870 and $187 \mathrm{I}$, thirty-six of the most trustworthy physicians of Belgium acquainted me with the results obtained by them in vaccinations and revaccinations with animal lymph on points sent out by the State Vaccine Institute at Brussels. These are the results: I. In vaccinations, out of a total of 500 cases, 479 successes, or 96 per cent.; 2. In revaccinations, out of a total of 5,425 cases, 3,419 successes, or 62 per cent., a result superior to those shewn in all statistics. In England, the best vaccinators only calculate upon 90 per cent. of success in vaccinations performed with human lymph in tubes, and 95 per cent. with the same lymph on ivory points.

I shall here finish what I have to say about statistics, without wishing on that account to cast any doubt or disparagement on the comparative figures adduced by men whose character I respect too much to think of doubting their sincerity.

But it is not sufficient to adduce figures: it is necessary to know at what time and under what conditions they have been brought together.

\footnotetext{
* Concluded from page 928 of last number.
} 